\title{
AUTOMATIC COOKER HOOD : PENGHISAP ASAP OTOMATIS PADA DAPUR BERBASIS KETEBALAN ASAP
}

\author{
Agus Waluyo ${ }^{1)}$, Aditya Ryadhi ${ }^{2)}$ dan Kamarudin ${ }^{3)}$ \\ 1,2,3 Teknik Elektro, Politeknik Negeri Batam, Batam Center, Jl. Ahmad Yani, Tlk. Tering, Batam Kota, \\ Kota Batam, Kepulauan Riau 29461 \\ E-mail: ${ }^{1}$ agus45waluyo@gmail.com
}

\begin{abstract}
Kitchen is a room to process food until ready to serve. A good and healthy kitchen should be kept clean. Excessive fumes from cooking will disrupt health. The cooker hood is a smoke suction device, generally still manual, the use of the control panel to set the cooker hood looks less practical, because it can not keep up with excessive smoke. From the problem the researcher make an automatic smoke suction system, if the smoke condition there is no dc motor will off, when detected dc motor smoke will be active with normal speed, when detected more smoke speed dc motor will faster spin. In this system use MQ7 sensor as an indication of the smoke, current sensor as an indication of current on the system. To adjust the speed of a DC motor the researcher uses a PID system, The motor speed changes according to the smoke condition. In this study is expected to facilitate the job when cooking proses and people who are cooking is not disturbed by the presence of excessive smoke.
\end{abstract}

Keywords: Motor DC, MQ7, Cooker Hood, Kitchen and PID.

\begin{abstract}
ABSTRAK
Dapur adalah suatu ruangan untuk mengolah makanan hingga siap di sajikan. Dapur yang baik dan sehat harus terjaga kebersihannya. Asap yang berlebihan dari hasil memasak akan mengganggu kesehatan. Cooker hood, merupakan alat penghisap asap, pada umumnya masih bersifat manual, penggunaan control panel untuk mengatur cooker hood terlihat kurang praktis, karena tidak bisa mengimbangi asap yang berlebih. Dari permasalahan tersebut peneliti membuat sebuah sistem penghisap asap otomatis, apabila kondisi asap tidak ada motor dc akan off, ketika terdeteksi adanya asap motor dc akan aktif dengan kecepatan normal, ketika terdeteksi asap lebih kecepatan motor dc akan lebih cepat berputar. Pada sistem ini menggunkan sensor MQ7 sebagai indikasi adanya asap, current sensor sebagai indikasi arus pada sistem. Untuk mengatur Kecepatan motor DC peneliti menggunakan sistem PID, Kecepatan motor berubah sesuai dengan kondisi asap. Pada penelitian ini diharapkan mempermudah perkerjaan saat peroses memasak dan orang yang sedang masak tidak terganggu dengan adanya asap berlebih.

Kata kunci : Motor DC, MQ7, Cooker Hood, Dapur, dan PID.
\end{abstract}

\section{PENDAHULUAN}

\section{Latar Belakang}

Dapur adalah suatu ruangan untuk mengolah makanan hingga siap di sajikan. Dapur yang baik dan sehat harus terjaga kebersihannya. Asap yang berlebihan dari hasil memasak akan mengganggu pernapasan. Cooker hood, merupakan alat penghisap asap, pada umumnya yang ada dipasaran masih bersifat manual, penggunaan control panel untuk mengatur cooker hood terlihat kurang praktis karena harus mengntrol kekuatan daya hisap exhaust fan secara manual dengan sistem manual tidak bisa mengimbangi asap yang berlebih.
Berdasarkan penelitian terdahulu, penulis bermaksud membuat sebuah sistem penghisap asap otomatis pada saat memasak Automatic Cooker Hood. Sistem ini akan berkerja secara otomatis dengan bantuan sensor pendeteksi asap, apabila tombol power on aktif. Sensor MQ7 mendeteksi adanya asap, apabila ada asap yang terdeteksi motor dc akan aktif secara otomatis, apabila asap yang terdeteksi semakin banyak maka motor dc akan lebih cepat berputar. Motor dc akan off secara otomatis apabila sensor MQ7 tidak mendeteksi adanya asap. Sensor MQ7 sebagai indikasi dalam pengaturan kecepatan daya hisap exhaust fan. Alat yang akan dirancang dilengkapi dengan 
filter partikel carbon aktif yang ampuh menghisap asap dan menetralisir bau tidak sedap.

Alat ini digunakan pada dapur, khususnya dapur yang tidak memiliki sirkulasi udara, agar asap saat proses memasak bisa dibuang keluar.

Alat penghisap asap Cooker Hood yang sudah ada saat ini masih manual, dengan demikan penulis menawarkan sebuah alat penghisap asap otomatis Automatic Cooker Hood. Yang mempermudahkan perkerjaan saat peroses memasak.

\section{Perumusan Masalah}

Berdasarkan uraian di atas, maka penulis merumuskan permasalahannya adalah bagaimana membuat alat penghisap asap secara otomatis untuk mengurangi polusi asap pada saat proses memasak di dapur.

\section{Tujuan Penelitian}

Penelitian ini bertujuan untuk mengurangi asap saat proses memasak, sehingga kesehatan orang yang sedang memasak tidak terganggu dengan adanya asap berlebih. Dan menghemat pemakain daya listrik.

\section{METODE PENELITIAN Rancangan Penelitian}

Bagian ini akan menjelaskan mengenai blok diagram rancangan Penelitian pada sistem ini secara garis besar. Rancangan sistem keseluruhan bertujuan untuk merealisasikan penghisapan asap secara otomatis, hal tersebut dapat dilihat pada blok diagram dibawah ini. Gambar 1.

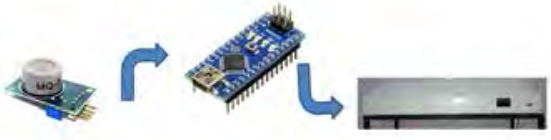

Gambar 1. Diagram Blok Perangkat Keras

Penjelasan blog diagram sebagai berikut : Automatic cooker hood secara garis besar memiliki fungsi untuk penghisapan asap secara otomatis. Dalam sistem ini menggunakan mikrokontroller sebagai pusat pengendali, yang telah diprogram kemudian membaca kondisi asap, dalam hal ini untuk membaca kondisi asap dikategorikan menjadi beberapa kondisi. Adapun kondisi tersebut ialah, tidak ada asap, ada asap, dan asap berlebih.

Ketika sensor mendeteksi adanya asap motor dc akan aktif secara otomatis, semakin banyak asap yang terdeteksi oleh sensor maka motor dc akan berputar lebih cepat dan apabila tidak ada asap yang terdeteksi oleh sensor maka motor dc akan off secara otomatis.

\section{Sistem Flowchart}

Flowchart dibawah ini merupakan alur kerja sistem secara umum. Alur diagram menjelaskan proses kerja sistem mulai hingga selesai. Selanjutnya proses yang dijalankan sensor untuk membaca kondisi asap dan mengirimkan data untuk mengoperasikan kecepatan motor dc. Hal tersebut dapat dilihat pada Flowchart proses kerja sistem pada Gambar 2. 


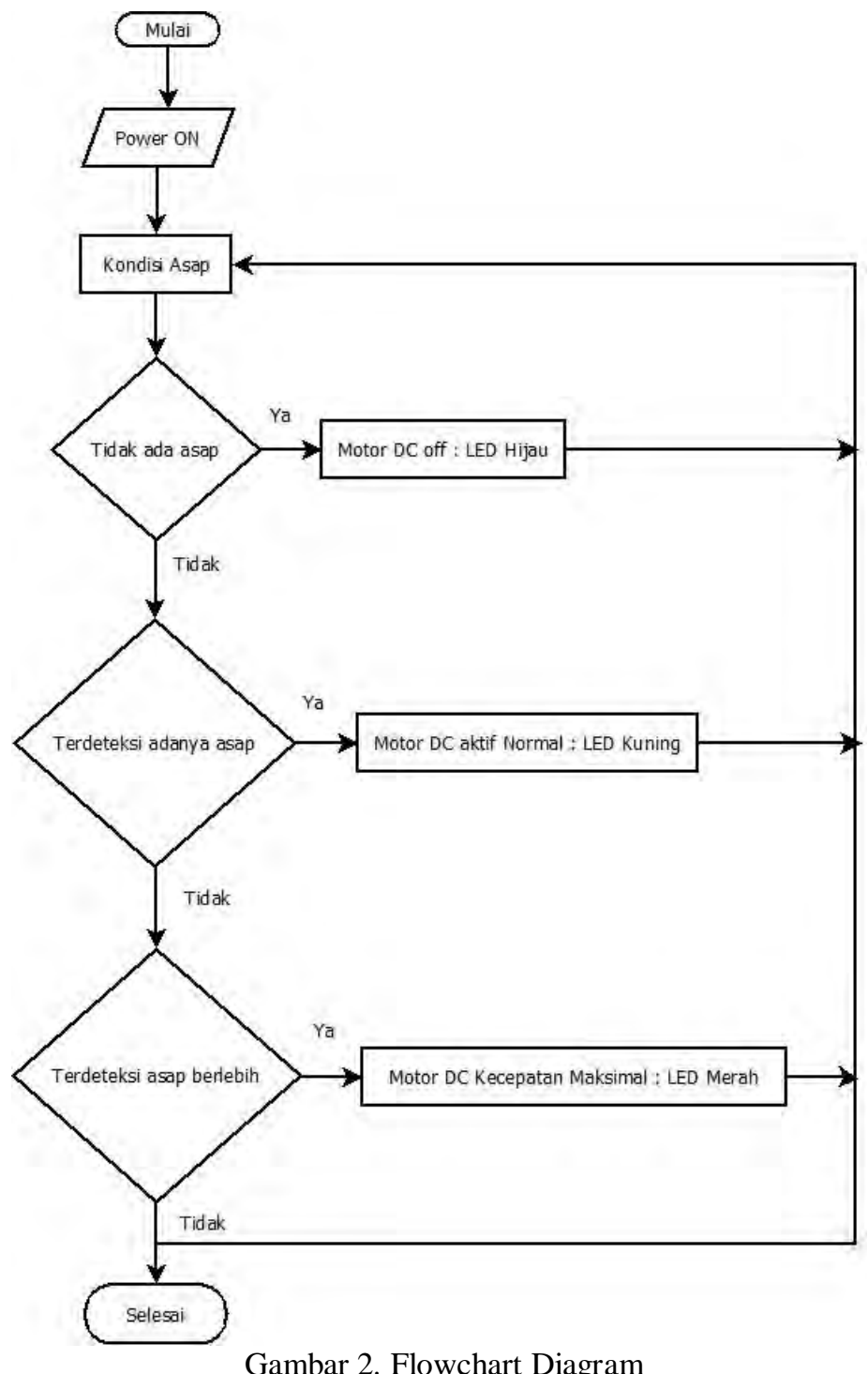

Gambar 2. Flowchart Diagram

Prinsip kerja dari sistem ini terlihat pada gambar 2, apabila tombol power on aktif. Sensor mendeteksi adanya asap, apabila ada asap yang terdeteksi motor dc akan aktif secara otomatis, apabila asap yang terdeteksi semakin banyak maka motor dc akan lebih cepat berputar. Motor dc akan off secara otomatis apabila sensor tidak mendeteksi adanya asap. Sensor sebagai indikasi dalam pengaturan kecepatan daya hisap motor dc.

\section{Perancangan Elektrikal}

Sistem Perancangan elektrikal Automatic Cooker Hood sistem adalah skema pemasangan sensor, catu daya sebagai supply tegangan, motor DC, dan mikrokontroler. Perancangan elektrikal Automatic Cooker Hood sistem dapat dilihat pada gambar 3.

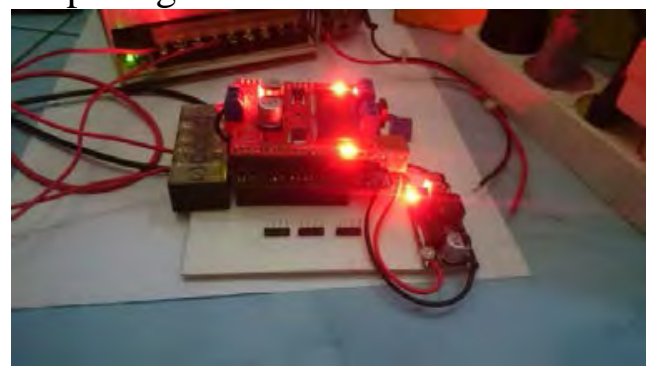

Gambar 3. Perancangan Elektrikal

Tegangan Sumber yang digunakan untuk komponen sensor yaitu sumber DC (Direct Current) 5V, yang didapat dari prosesor. Proses dalam penelitian ini menggunakan komponen prosessor yang mendapat sumber 5V dari DC Power Suplay. Sedangkan pada proses input motor DC diberi sumber tegangan 
12VDC yang di kontrol dengan bantuan komponen driver motor.

\section{Kontrol PID}

Sistem Kontrol yang digunakan pada Automatic Cooker Hood adalah PID. PID digunakan untuk menentukan kecepatan motor yang dipengaruhi oleh ketebalan asap. Kontrol $\mathrm{Kp}$ digunakan untuk mempercepat respon star saat sensor membaca ketebalan asap. Kontrol Ki digunakan untuk menjaga kecepatan motor sesuai dengan ketebalan asap yang terbaca oleh sensor. Kontrol Kd digunakan untuk menjaga kecepatan motor selama jangka waktu yang telah ditentukan diprogram.

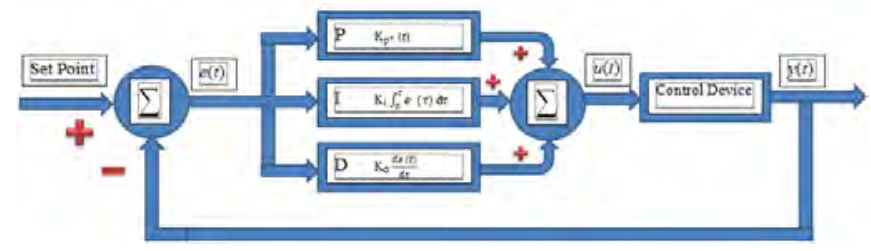

Gambar 4. Blok Diagram PID

HASIL DAN PEMBAHASAN

Data pamakaian daya listrik

Tabel 1.Data pemakaian daya listrik per 30 menit

\begin{tabular}{|l|l|l|l|l|}
\hline No. & Waktu & $\begin{array}{l}\text { Daya 100 } \\
\text { Watt }\end{array}$ & $\begin{array}{l}\text { Daya 200 } \\
\text { Watt }\end{array}$ & $\begin{array}{l}\text { Daya } \\
\text { Watt }\end{array}$ \\
\hline 1 & 30 Menit & $0.041 \mathrm{kWh}$ & $0.083 \mathrm{kWh}$ & $0.0075 \mathrm{kWh}$ \\
\hline 2 & 60 Menit & $0.083 \mathrm{kWh}$ & $0.16 \mathrm{kWh}$ & $0.015 \mathrm{kWh}$ \\
\hline 3 & 90 Menit & $0.12 \mathrm{kWh}$ & $0.24 \mathrm{kWh}$ & $0.022 \mathrm{kWh}$ \\
\hline 4 & 120 Menit & $0.16 \mathrm{kWh}$ & $0.33 \mathrm{kWh}$ & $0.030 \mathrm{kWh}$ \\
\hline 5 & 150 Menit & $0.20 \mathrm{kWh}$ & $0.41 \mathrm{kWh}$ & $0.037 \mathrm{kWh}$ \\
\hline 6 & 180 Menit & $0.24 \mathrm{kWh}$ & $0.49 \mathrm{kWh}$ & $0.045 \mathrm{kWh}$ \\
\hline
\end{tabular}

Analisa pemakaian daya listrik per 30 menit

\begin{tabular}{|c|c|c|}
\hline 100 watt & 200 watt & 15 watt \\
\hline$P \quad P \quad t p$ & $\mathrm{x}=\frac{P}{t p}$ & $\mathrm{x}=\frac{P}{t p}$ \\
\hline $\mathrm{x}=\overline{1000}^{x} \bar{t}$ & $\mathrm{x}=\overline{1000}^{2} \bar{t}$ & $\mathrm{x}=\frac{\overline{1000}}{x} \bar{t}$ \\
\hline $\mathrm{x}=\frac{100}{30}$ & $x=20030$ & $15 \quad 30$ \\
\hline $\mathrm{x}=\overline{1000} \times \overline{60}$ & $\mathrm{x}=\overline{1000} \times \overline{60}$ & $\mathrm{x}=\overline{1000} x \overline{60}$ \\
\hline $\mathrm{x}=0.1 \times 0.5$ & $\mathrm{x}=0.2 \times 0.5$ & $\mathrm{x}=0.015 \times 0.5$ \\
\hline $\mathrm{x}=0.05 \times p f$ & $\mathrm{x}=0.1 \times p f$ & $\mathrm{x}=0.0075 k W h$ \\
\hline $\mathrm{x}=0.05 \times 0.83$ & $\mathrm{x}=0.1 \times 0.83$ & \\
\hline $\mathrm{x}=0.041 \mathrm{kWh}$ & $\mathrm{x}=0.083 \mathrm{kWh}$ & \\
\hline$P \quad t p$ & $P \quad t p$ & $t p$ \\
\hline $\mathrm{x}=\overline{1000} \times \frac{1}{t}$ & $\mathrm{x}=\overline{1000} \times \frac{\dot{t}}{t}$ & $\mathrm{x}=\overline{1000} \times \frac{1}{t}$ \\
\hline $\begin{array}{ll}100 & 60\end{array}$ & $200 \quad 60$ & $15 \quad 60$ \\
\hline $\mathrm{x}=\overline{1000} \times \overline{60}$ & $\mathrm{x}=\overline{1000} \times \overline{60}$ & $\mathrm{x}=\frac{\overline{1000}}{10} \overline{60}$ \\
\hline $\mathrm{x}=0.1 \times 1$ & $\mathrm{x}=0.2 \times 1$ & $\mathrm{x}=0.015 \times 1$ \\
\hline $\mathrm{x}=0.1 \times p f$ & $\mathrm{x}=0.2 \times p f$ & $\mathrm{x}=0.015 \mathrm{kWh}$ \\
\hline $\mathrm{x}=0.1 \times 0.83$ & $\mathrm{x}=0.2 \times 0.83$ & \\
\hline $\mathrm{x}=0.083 \mathrm{kWh}$ & $\mathrm{x}=0.16 k W h$ & \\
\hline $\mathrm{x}=\frac{P}{t p}$ & $P \quad t p$ & $P \quad x \underline{t p}$ \\
\hline$x=\overline{1000} \times \bar{t}$ & $x=\frac{1000}{x} \bar{t}$ & $\overline{1000} \times \bar{t}$ \\
\hline $100 \quad 90$ & $200 \quad 90$ & 90 \\
\hline $\mathrm{x}=\frac{}{1000} \times \frac{0}{60}$ & $\mathrm{x}=\frac{}{1000} \times \frac{0}{60}$ & $\mathrm{x}=\frac{10}{1000} \times \frac{0}{60}$ \\
\hline $\mathrm{x}=0.1 \times 1.5$ & $\mathrm{x}=0.2 \times 1.5$ & $x=0.015 \times 1.5$ \\
\hline $\mathrm{x}=0.15 \times p f$ & $\mathrm{x}=0.3 \times p f$ & $\mathrm{x}=0.022 \mathrm{kWh}$ \\
\hline$x=0.15 \times 0.83$ & $\mathrm{x}=0.3 \times 0.83$ & \\
\hline $\mathrm{x}=0.12 \mathrm{kWh}$ & $\mathrm{x}=0.24 k W h$ & \\
\hline$P \quad t p$ & $P \quad t p$ & $P \quad t p$ \\
\hline $\mathrm{x}=\overline{1000} \times \frac{\bar{t}}{t}$ & $\mathrm{x}=\overline{1000}^{x} \bar{t}$ & $\mathrm{x}=\frac{\overline{1000}}{x} \bar{t}$ \\
\hline $\begin{array}{ll}100 & 120\end{array}$ & $200 \quad 120$ & $\begin{array}{ll}15 & 120\end{array}$ \\
\hline$x=\frac{1000}{100} \frac{}{60}$ & $\mathrm{x}=\frac{\overline{1000}}{\mathrm{~N}} \times \frac{\overline{60}}{60}$ & $x=\frac{}{1000} \times \frac{}{60}$ \\
\hline$x=0.1 \times 2$ & $x=0.2 \times 2$ & $x=0.015 \times 2$ \\
\hline $\mathrm{x}=0.2 \times \mathrm{pf}$ & $\mathrm{x}=0.4 x p f$ & $\mathrm{x}=0.030 \mathrm{kWh}$ \\
\hline $\mathrm{x}=0.2 \times 0.83$ & $\mathrm{x}=0.4 \times 0.83$ & \\
\hline $\mathrm{x}=0.16 \mathrm{kWh}$ & $\mathrm{x}=0.33 \mathrm{kWh}$ & \\
\hline $\mathrm{x}=\frac{P}{t} x \underline{t p}$ & $\mathrm{x}=\frac{P}{t} x \underline{t p}$ & $\mathrm{x}=\frac{P}{t} x \underline{t p}$ \\
\hline$x=\frac{1000}{10} \bar{t}$ & $x=\frac{1000}{10} \bar{t}$ & $x=\frac{1000}{10} \bar{t}$ \\
\hline
\end{tabular}

\begin{tabular}{|l|l|l|}
\hline $\mathrm{x}=\frac{100}{1000} \times \frac{150}{60}$ & $\mathrm{x}=\frac{200}{1000} \times \frac{150}{60}$ & $\mathrm{x}=\frac{15}{1000} \times \frac{150}{60}$ \\
$\mathrm{x}=0.1 \times 2.5$ & $\mathrm{x}=0.2 \times 2.5$ & $\mathrm{x}=0.015 \times 2.5$ \\
$\mathrm{x}=0.25 \times \mathrm{pf}$ & $\mathrm{x}=0.5 \times \mathrm{pf}$ \\
$\mathrm{x}=0.25 \times 0.83$ & $\mathrm{x}=0.5 \times 0.83$ \\
$\mathrm{x}=0.20 \mathrm{kWh}$ & $\mathrm{x}=0.41 \mathrm{kWh}$ & \\
\hline $\mathrm{x}=\frac{P}{1000} \times \frac{t p}{t}$ & $\mathrm{x}=\frac{P}{1000} \times \frac{t p}{t}$ & $\mathrm{x}=\frac{P}{1000} \times \frac{t p}{t}$ \\
$\mathrm{x}=\frac{100}{1000} \times \frac{180}{60}$ & $\mathrm{x}=\frac{200}{1000} \times \frac{180}{60}$ & $\mathrm{x}=\frac{15}{1000} \times \frac{180}{60}$ \\
$\mathrm{x}=0.1 \times 3$ & $\mathrm{x}=0.2 \times 3$ & $\mathrm{x}=0.015 \times 3$ \\
$\mathrm{x}=0.3 \times \mathrm{pf}$ & $\mathrm{x}=0.6 \times \mathrm{pf}$ \\
$\mathrm{x}=0.3 \times 0.83$ & $\mathrm{x}=0.6 \times 0.83$ \\
$\mathrm{x}=0.24 \mathrm{kWh}$ & $\mathrm{x}=0.49 \mathrm{kWh}$ & \\
\hline
\end{tabular}

$P=$ daya(watt)

$t p$ = lamanya Waktu Percobaan (menit)

$P f=$ faktor daya (0.83)

$t=$ waktu (menit)

Tabel 2 Data pemakaian daya listrik 30 hari

\begin{tabular}{|l|l|l|l|}
\hline No. & Daya & $\begin{array}{l}\text { Pemakaian } \\
\text { Perhari (90 Menit) }\end{array}$ & $\begin{array}{l}\text { Pemakaian } \\
\text { Sebulan }\end{array}$ \\
\hline 1 & $\begin{array}{l}100 \\
\text { Watt }\end{array}$ & $0.15 \mathrm{kWh}$ & $4.5 \mathrm{kWh}$ \\
\hline 2 & $\begin{array}{l}200 \\
\text { Watt }\end{array}$ & $0.3 \mathrm{kWh}$ & $9 \mathrm{kWh}$ \\
\hline 3 & $15 \mathrm{Watt}$ & $0.0225 \mathrm{kWh}$ & $0.675 \mathrm{kWh}$ \\
\hline
\end{tabular}

Analisa pemakaian daya listrik 30 hari

\begin{tabular}{|c|c|c|}
\hline 100 watt & 200 watt & 15 watt \\
\hline $\mathrm{x}=\frac{P}{1000} \times \frac{l p}{t}$ & $\mathrm{x}=\frac{P}{1000} \times \frac{l p}{t}$ & $\mathrm{x}=\frac{P}{1000} \times \frac{t p}{t}$ \\
\hline $\mathrm{x}=\frac{100}{1000} \times \frac{90}{60}$ & $\mathrm{x}=\frac{200}{1000} \times \frac{90}{60}$ & $\mathrm{x}=\frac{15}{1000} \times \frac{90}{60}$ \\
\hline $\mathrm{x}=0.1 \times 1.5$ & $\mathrm{x}=0.2 \times 1.5$ & $\mathrm{x}=0.015 \times 1.5$ \\
\hline $\begin{array}{l}x \\
=0.15 \mathrm{kWh} \times 30 \text { hari } \\
\mathrm{x}=4.5 \mathrm{kWh}\end{array}$ & $\begin{array}{l}\mathrm{x} \\
=0.3 \mathrm{kWh} \times 30 \text { hari } \\
\mathrm{x}=9 \mathrm{kWh}\end{array}$ & $\begin{array}{l}\mathrm{x} \\
=0.0225 \mathrm{kWh} \times 30 \text { hari } \\
\mathrm{x}=0.67 \mathrm{kWh}\end{array}$ \\
\hline \multicolumn{3}{|c|}{$P=$ daya(watt) } \\
\hline \multicolumn{3}{|c|}{ lp = lamanya pemakaian perhari (menit) } \\
\hline \multicolumn{3}{|c|}{$P f=$ faktor daya $(0.83)$} \\
\hline \multicolumn{3}{|c|}{$t=$ waktu (menit) } \\
\hline
\end{tabular}




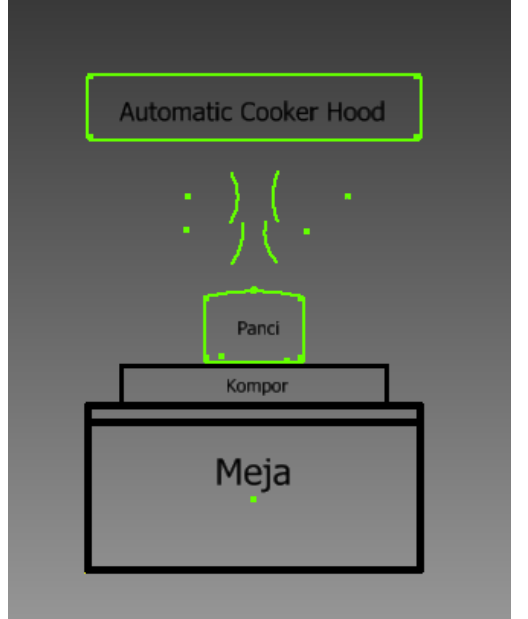

Gambar 5. Tata letak Automatic Cooker Hood

\section{KESIMPULAN}

Berdasarkan hasil analisa dan pembahasan maka dapat disimpulkan sebagai berikut:

1. Automatic Cooker Hood mampu mengimbagi asap pada saat peroses memasak.

2. Pemakaian daya listrik lebih hemat.

3. Ramah lingkungan

4. Mudah di operasikan

\section{DAFTAR PUSTAKA}

[1] Arifin, J. and Zulita, L.N., 2016. Perancangan Murottal Otomatis Menggunakan Mikrokontroller Arduino Mega 2560. Media Infotama, 12(1)

[2] Arihutomo, M., Rivai, M. and Suwito, S., 2012. Sistem monitoring arus listrik jala-jala menggunakan Power Line Carrier. Jurnal Teknik ITS, 1(1), pp.A150-A153.

[3] Kamarudin, P, Endra, \& Dewanto, S.R. June 30, 2016. 3D Independent Actuators

Control Based On A Proportional Deriv ative Active Force Control. Journal of Ocean, Mechanical and Aerospace, Science and Engineering, Vol.32
[4] Putro, I.A.E. and Abadi, I., 2012. Rancang Bangun Alat Uukur Emisi Gas Buang, Studi Kasus: Pengukuran Gas Karbon Monoksida (CO). digital library ITS paper, surabaya.

[5] Nebath, E., Pang, D. and Wuwung, J.O., 2014. Rancang Bangun Alat Pengukur Gas Berbahaya CO Dan CO2 di Lingkungan Industri. E-Journal Teknik Elektro Dan Komputer, 3(4), pp.65-72.

[6] Ya'kut, H.A., Wardoyo, A.Y.P. and Dharmawan, H.A., Rancang Bangun Sistem Pengukur Gas Karbon Monoksida (Co) Menggunakan Sensor Mq-7 Berbasis Mikrokontroler Atmega 16a. Brawijaya Physics Student Journal, 2(1). 
Agus Waluyo, Aditya Ryadhi dan Kamarudin, Automatic Cooker Hood... 